\title{
Nutritional Status of 35 Elderly People Residing in a Nursing Home: A Dual Challenge of Energy Surplus and Nutrient Insufficiency
}

\author{
Jin Wang ${ }^{1 *}$, Yi-Wen Liu², Ainiwaer Aikebaier ${ }^{2}$, Zhen Tong ${ }^{2}$, Yan Zhang ${ }^{2}$ and Hong-Wei Guo ${ }^{3}$ \\ ${ }^{1}$ College of Chemistry, Chemical Engineering and Biotechnology, Donghua University, Shanghai 201620, China \\ ${ }^{2}$ Department of Clinical Medicine, Shanghai Medical School, Fudan University, Shanghai 200032, China
}

${ }^{3}$ Department of Nutrition and Food Hygiene, School of Public Health, Fudan University, Shanghai 200032, China

\begin{abstract}
To elaborate the implications underlying dietary nutrition and physical activity, and give a reasonable advice for the elderly to acquire an ideal body weight. 35 older individuals aged 65 years and above were applied to conduct a nutritional survey and estimate energy expenditure for the elderly in a nursing home by a weighed- food recording, anthropometry and factorial calculation. Intakes of energy, carbohydrate, protein, fat, thiamine and riboflavin were $(5.63 \pm 1.32) \mathrm{MJ},(193.8 \pm 51.3) \mathrm{g},(45.2 \pm 9.9) \mathrm{g},(43.3 \pm 11.6) \mathrm{g},(0.82 \pm 0.25) \mathrm{mg}$ and $(0.46 \pm 0.15)$ mg, respectively. The sample fraction of inadequate intakes of energy, protein, thiamine and riboflavin compared with the recommended levels in terms of 2000 Chinese Dietary Reference Intakes was $88.6 \%, 77.1 \%, 88.6 \%$ and $100 \%$, respectively.

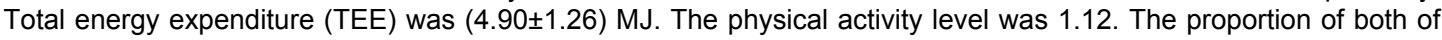
overweight and obesity based on body mass index (BMI) was $48.6 \%$. The average of physical activity level (PAL) and nutritional status for the sampling older adults was lower compared with recommendations of 2000 Chinese Dietary Reference Intakes, but the mean energy intake did exceed the mean energy expenditure. Consequently, the elderly subjects should increase their PAL and their dietary intakes so that they can reach their own energy balance and their nutrient consumption is able to meet their nutrient requirements.
\end{abstract}

Keywords: Energy metabolism; Physical activity level; Body mass index; Nutritional requirements; Malnutrition; Senior adults

Abbreviations: BMI: Body Mass Index; BEE: Basal Energy Expenditure; PAL: Physical Activity Levels; BMR: Basal Metabolic Rate; PAR: Physical Activity Ratio; TEE: Total Energy Expenditure

\section{Introduction}

The ability to control dietary energy intake becomes impaired with age, even in healthy older adults [1]. This problem, in conjunction with reduction in total energy expenditure mainly due to decrement of resting energy expenditure and activity-induced energy expenditure, chronic diseases, chewing problems, polypharmacy, living alone, and low income, likely explains the high vulnerability of the elderly population to energy imbalances [2]. The chronic energy imbalance between feeding and expenditure leads to undesirable changes of body weight and body composition, i.e. weight gain or weight loss, and reductions in skeletal muscle and corresponding increases in visceral adipose tissue and intermuscular adipose tissue [3]. The imbalance further contributes to the progressive decline of physical performance and the development of age-associated chronic degenerative diseases, which ultimately increases the risk for premature mortality $[2,4]$. Fortunately, recent observations show that objectively measured freeliving activity-induced energy expenditure is strongly associated with lower risk of mortality in healthy older adults [5]. Thus, simply spending energy through daily physical activity may confer survival advantages in older adults by improving body composition and physical fitness [57].

Adequate total energy expenditure in healthy elderly subjects due to a right energy expenditure of physical activities has important implications for nutritional requirements, guidelines, and recommendations. The food and energy intake of elderly subjects should be appropriate to preventing weight loss and micronutrient deficiencies but should also preclude overweight and obesity. It was reported by the Follow-up Study on Transition of Dietary Pattern and Nutritional Status in Chinese Residents [8] that consumptions of total food and intakes of energy, protein and thiamin appeared a downtrend in the Chinese elderly population between 1991-2004, and that of energy was enough, but that of riboflavin was insufficient. However, during a period of the same time, the rate of overweight and obesity based on body mass index (BMI) in the middle-aged and older residents in China rapidly increased. This inconsistency could be partly explained by the hypothesis that a lower level of physical activities resulted in a lower expenditure of total energy in those age groups, which might cause energy over plus in their body and embody overweight and obesity. Therefore, in a group of 35 elderly persons residing in a nursing home, we assessed their nutritional adequacy of dietary nutrient intakes; specifically investigated their total energy expenditure (TEE) derived from predictive equations of basal energy expenditure (BEE) and their physical activity level (PAL) in such a sampling population.

\section{Methods and Materials}

\section{Subjects}

Subjects aged 60 years or older from a nursing home in the Shanghai municipal district were recruited by administrators' spoken communication. 36 apparently healthy elderly volunteers who had no significant acute medical problems participated in this study after administrators of the nursing home informed all older people living in the establishment the study plan. Before acceptance into the study, each subject completes an evaluation of health status by means of a medical questionnaire checked by a physician. Excluded from this study were

*Corresponding author: Jin Wang, College of Chemistry, Chemical Engineering and Biotechnology, Donghua University, Shanghai 201620, China E-mail: jwang@shmu.edu.cn

Received November 13, 2011; Accepted January 21, 2012; Published January 23, 2012

Citation: Wang J, Liu Y, Aikebaier A, Tong Z, Zhang Y, et al. (2012) Nutritional Status of 35 Elderly People Residing in a Nursing Home: A Dual Challenge of Energy Surplus and Nutrient Insufficiency. J Nutr Disorders Ther S5:001. doi:10.4172/2161-0509.S5-001

Copyright: ( 2012 Wang J, et al. This is an open-access article distributed under the terms of the Creative Commons Attribution License, which permits unrestricted use, distribution, and reproduction in any medium, provided the original author and source are credited. 
Citation: Wang J, Liu Y, Aikebaier A, Tong Z, Zhang Y, et al. (2012) Nutritional Status of 35 Elderly People Residing in a Nursing Home: A Dual Challenge of Energy Surplus and Nutrient Insufficiency. J Nutr Disorders Ther S5:001. doi:10.4172/2161-0509.S5-001

Page 2 of 4

smokers, regular alcohol users, subjects taking medication (e.g., $\beta$-blockers), and subjects with a hypo-energetic or hyper-energetic diet that could influence energy expenditure. Subjects using multivitamins and trace element supplements for at least four weeks prior the study were excluded. Subjects with serious diseases or disabilities that could interfere with the performance of physical activities during the study were excluded. We also excluded any individual who was unable to perform all measurements for personal reasons. Finally, 35 subjects $(6$ male and 29 female) aged 65 to 98 years were selected for this study. After receiving complete written and verbal explanations of the study, all subjects signed an informed-consent document. The study protocol and informed-consent document were reviewed and approved by the Ethics Committee of the Fudan University.

\section{Dietary survey}

A consecutive 5-day dietary intake using a detailed, precise weighed-food record with digital weighing machines was conducted for each subject by a trained cook and trained interviewers. The investigator checked the records of dietary consumptions for each subject every day so that doubtful recording data were able to be corrected in time. The weight of all foods and beverages before and after ingestion for each subject was quantified to assess the actual intake of diet by weighing the food or beverage on scales. The weight of used raw food and cooked food in the kitchen were also measured in order to compute a ratio of the weight of raw material to the weight of cooked food. The consumption of energy and nutrients was calculated in terms of Chinese Food Composition Table $[9,10]$.

\section{Anthropometry}

All anthropometric measurements were made after voiding, with the subjects wearing underwear. Body weight was measured to the nearest $0.1 \mathrm{~kg}$ using a digital scale. Height without shoes was measured to the nearest $0.001 \mathrm{~m}$ using a wall-mounted stadiometer. BMI was calculated as weight in kilograms divided by height in meters squared. The classification of body mass index for Chinese adults is: below $18.5 \mathrm{~kg} / \mathrm{m}^{2}$ (underweight), 18.5 to 23.9 (normal weight), 24.0-27.9 (overweight), and equal to or more than $28.0 \mathrm{~kg} / \mathrm{m}^{2}$ (obesity) [11]. Prevalence of BMI values both of below $18.5 \mathrm{~kg} / \mathrm{m}^{2}$ (underweight) and equal or above $24.0 \mathrm{~kg} / \mathrm{m}^{2}$ (overweight and obesity) was calculated.

\section{Energy expenditure estimation}

Subjects kept a free-living condition, and physical activity diaries were used to estimate their energy expenditure by trained interviewers. Physical activity diaries included activity categories and the sum of time spent on each activity category. TEE was calculated by multiplying the sum of the hours spent on each activity item with the physical activity ratio (PAR = TEE for each activity/BEE) of each activity item and with estimated BMR values. For this purpose, $\mathrm{FAO} / \mathrm{WHO} / \mathrm{UNU}$ factors were used (to follow) $[12,13]$. A consecutive 5-day diary of habitual physical activity of subjects was conducted by trained interviewers. The diary was recorded as activity items and total time spent on each activity item. An average value of sum of time spent on each activity item of 5 days per capita was calculated. Energy requirement of subjects was estimated by means of the factorial calculation recommended by the $\mathrm{WHO}$ report $[12,13]$. Consequently, TEE $=\mathrm{BMR} \times \mathrm{PAR} \times$ average activity time. Meanwhile, because of overestimation of BMR for Chinese adults by the empirically adjusted Schofield equation (down-adjusted by $5 \%$ ) adopted by the panel of experts for dietary reference intakes for Chinese residents in year $2000[14,15]$, we used the predictive equation for BMR in Chinese adults developed by scholars in Chinese Taiwan [16] to calculate basal energy expenditure (BEE). That is, BEE (MJ/d)
$=0.0581 \times$ weight $(\mathrm{kg})+1.7405 \times$ height $(\mathrm{m})-0.0144 \times$ age (years) $0.4703 \times$ gender $($ male $=0$, female $=1)+0.2274$.

\section{Statistical analysis}

Values for all results were expressed as mean \pm standard deviation if normality test passed. Otherwise, results were presented as median $\left(P_{25}, P_{75}\right)$. Analyses of differences between groups were performed using a paired Student $t$ test. According to Chinese Food Composition Table $[9,10]$, consumptions of energy and nutrients of individuals were computed using Microsoft Excel 2000 software (Microsoft Corporation). Two-sided $P$ values less than 0.05 were considered significant unless otherwise indicted. All data were analyzed using SPSS version 15.0 (SPSS, Chicago, IL). Kolomogorov-Simirnov onesample test was used to test a normal distribution, and paired-samples $t$ test was used to test differences between treatments.

\section{Results}

\section{Subject characteristics and anthropometrics}

Subjects' mean age was $85.5 \pm 7.0$ years, and the age range was from 65 to 98 years. The percent of female was $82.9 \%$, and that of male was $17.1 \%$. According to the classification of body mass index for Chinese adults, constituent ratios of underweight, normal weight, overweight and adiposity were $14.3 \%, 37.1 \%, 34.3 \%$ and $14.3 \%$, respectively. The rate of abnormal weight categories (including underweight, overweight and obesity) was $62.9 \%$, most of which was overweight and obesity indicating energy excess (together accounting for $48.6 \%$ ).

\section{Dietary assessment}

Intakes of energy, carbohydrate, protein, fat, thiamin and riboflavin of 35 subjects were $5.63 \pm 1.32(\mathrm{MJ}), 193.8 \pm 51.3(\mathrm{~g}), 45.2 \pm 9.9$ (g), $43.3 \pm 11.6(\mathrm{~g}), 0.82 \pm 0.25(\mathrm{mg})$, and $0.46 \pm 0.15(\mathrm{mg})$, respectively; and carbohydrates, proteins, and total fat provided 57.6\%, $13.4 \%$, and $29.0 \%$ of energy intake, respectively. Compared with Chinese dietary reference intakes in 2000 for elderly people over the age of 80 [13], the prevalence of inadequate intake of energy, protein, thiamin and riboflavin was $88.6 \%, 77.1 \%, 88.6 \%$, and $100 \%$, respectively; and the proportion of energy consumed from carbohydrate and fat was acceptable (acceptable ranges for carbohydrate and fat: 54\%-65\% and

\begin{tabular}{|c|c|c|c|}
\hline Activity item & $\begin{array}{l}\text { Time }(h) \\
\text { (1) }\end{array}$ & $\begin{array}{l}P A R_{\text {证 }}[12.13] \\
\text { (2) }\end{array}$ & $\begin{array}{c}\text { (3) } \\
\text { (1) } \times(2)\end{array}$ \\
\hline Sleep & $14.30(13.48,15.29)$ & 1.0 & $\begin{array}{c}14.30 \\
(13.48,15.29)\end{array}$ \\
\hline Sitting quietly & $5.33 \pm 3.21$ & 1.2 & $6.40 \pm 3.86$ \\
\hline $\begin{array}{l}\text { Light leisure activities } \\
\text { (reading, watching } \\
\text { television, and chatting) }\end{array}$ & $0.00(0.00,1.22)$ & 1.4 & $0.00(0.00,1.70)$ \\
\hline Taking food & $2.09 \pm 0.45$ & 1.5 & $3.14 \pm 0.68$ \\
\hline $\begin{array}{l}\text { Self-caregiving (getting up, } \\
\text { taking a shower, washing } \\
\text { clothes, bodily limbs } \\
\text { movement) }\end{array}$ & $0.15(0.15,0.28)$ & 2.3 & $0.34(0.34,0.65)$ \\
\hline Promenade & $0.00(0.00,0.00)$ & 3.2 & $0.00(0.00,0.00)$ \\
\hline \multicolumn{4}{|c|}{$\operatorname{PAL} \odot=\sum(3)=1.12(1.10,1.15)$} \\
\hline \multicolumn{4}{|c|}{$\operatorname{BEE}(\mathrm{MJ} / \mathrm{d})=4.30 \pm 0.95$} \\
\hline \multicolumn{4}{|c|}{$\operatorname{TEE}(\mathrm{MJ} / \mathrm{d})=\mathrm{PAL} \times \mathrm{BEE}=4.90 \pm 1.26$} \\
\hline
\end{tabular}

Abbreviations: PAR, physical activity ratio; PAL, physical activity level; BEE, basa energy expenditure; TEE, total energy expenditure.

* : Values are expressed as $\bar{x} \pm \mathrm{SD}$ or median $\left(P_{25}, P_{75}\right)$.

is: $\mathrm{PAR}=\mathrm{TEE}$ for each activity /BEE.

() : $\mathrm{PAL}=24$-hour TEE/24-hour BEE.

Table1: 24 -hour TEE calculations using a factorial calculation method $(n=35)^{*}$. 
$20 \%-30 \%$ ), whereas the proportion of energy consumed from protein was lightly lower (acceptable range for protein: 15\%-16\%.).

\section{Physical activity level and total energy expenditure}

The daily PAL for subjects was 1.12, which was lower than the value of 1.49 classified to the light PAL for Chinese elderly people [13] as well as the $\mathrm{FAO} / \mathrm{WHO} / \mathrm{UNU}$ reference value of 1.5 classified to the very light PAL category [12]. Table 1 listed physical activity items daily performed by subjects and the result for TEE as estimated based on the predictive equation for BEE. Then, the TEE for subjects was significantly lower than their dietary intake of energy $(t=3.938$, $\mathrm{P}<0.001$ ), which indicated a positive energy balance between energy intake and expenditure. This status of energy excess was probable to explain the reason why the constituent ratio of both of the overweight and adipose individuals among classifying categories based on BMI was overwhelming. If estimated BEE of the subjects using the Schofield equation (down adjusted by $5 \%$ ) [13], the BEE of the subjects was $4.63 \pm 0.62(\mathrm{MJ} / \mathrm{d})$, corresponding to TEE as $5.27 \pm 0.92(\mathrm{MJ} / \mathrm{d})$ which remained lower than the current energy intake $(t=2.203, P=0.034)$.

If it was adopted that light PAL for reference elderly people as 1.49 to estimate the TEE of subjects, the values for total energy expenditure derived from the adjusted Schofield equation and the predictive equation developed by Chinese Taiwan scholars [16] were $6.92 \pm 0.93$ $(\mathrm{MJ} / \mathrm{d})$ and $6.43 \pm 1.43(\mathrm{MJ} / \mathrm{d})$, respectively. Both of the two estimated values for TEE were higher than the current energy intake $(t=7.054$, $P=0.001$; and $t=3.599, P=0.001$ ), which was consistent with the result as compared with the recommended nutrient intake for energy.

\section{Discussion}

The study population was a very-old age elderly group [17]. As compared with the Chinese dietary reference intakes for the elderly, they had an inadequate intake of nutritional components such as energy, protein, and some of water-soluble B vitamins (for example, thiamine and riboflavin) which were vulnerable to insufficient intake for the Chinese senior, but their anthropometric parameters paradoxically showed the presence of excessive fatty tissue. Our results almost coincide with those from a Polish study for free-living elderly people [18]. Our results also showed that the study population presented an energy imbalance being predominantly an energy excess, but micronutrient needs for older adults does not decrease proportionally with energy needs [19], thus it is further revealed that the dietary nutritional quality of the subjects is very poor including a dual problems of nutritional inadequacy and over plus. In the present study, the TEE was estimated by the BEE measured with the predictive equation, in combination with PAL. Because the average PAL for the study population was very low closely falling into a resting state (physical activity level=1.0), which suggested that the subjects were almost immobilized, there was a relatively high proportion of overweight and obesity although their insufficient prevalence of energy intake seemed to be higher as compared with the recommended nutrient intake for energy, which could be explained by subjects getting used to a sedentary lifestyle and a low energy cost, and a consequent energy excess and an increase of body weight.

A decline in the cellular fraction of fat-free mass of a highly metabolic tissue in elderly adults, and an age-related remodeling phenomenon of body composition with reductions in skeletal muscle and corresponding increases in visceral adipose tissue and intermuscular adipose tissue are observed with senescence, irrespective of sex or race [20-22]. Furthermore, the World Health Organization, the National Institutes of Health, and other groups have proposed that BMI values below or above a normal range increase the risk for premature mortality [2325]. The precise energy intake needed for optimal health and function likely depends on individual genetic background, age, energy cost, and dietary pattern [4]. In the present study, when we used the PAL for a reference man to estimate the TEE instead of that for the current subjects, the TEE exceeded the energy intake, which was consistent with the result of dietary evaluation. Therefore, the factor of PAL could be a critical determinant limiting the nutritional status for this elderly population being similar to the present study subjects. The Health Professionals' Follow-up study [26] demonstrates that the importance of physical activity to prevent weight gain with ageing. In this study an increase of $\geq 0.5 \mathrm{hr} /$ week in weight training was associated with a reduction in waist of $0.91 \mathrm{~cm}$. In a British study [27] a relationship was found between physical activity and change in body weight and fat mass over a 5.6 year follow up period in healthy men and women with a mean age of 54 years. Because low physical activity is a risk factor for obesity with increasing age [28], special attention should be given to interventions that increase physical activity in the elderly. Prevention programs should be tailored to the elderly population and make use of suitable and realistic multi media strategies. With respect to diet, strategies should be focused on a balanced diet, energy density, fruit and fibre, meal frequency. With respect to physical activity, emphasis should be given to including physical activity in normal daily activities and light to moderate aerobic exercises such as walking, household jobs, gardening, bicycling, Eight Diagrams Boxing, Taijiquan Boxing, and dumb-bell drills. In addition, based on a view of health promotion and an extensive review [29], it has become clear that solely providing a health message is not sufficient in improving people behavior. It is important that the environment of the elderly is equipped in such a way that it makes it possible or more easy to regularly exercise and to eat a healthy diet. There is a need for a systematically planned and integrated approach addressing both food consumption patterns and physical activity to reduce the risk of many chronic diseases such as obesity, sacropenia, hip fracture, stroke, dementia, diabetes mellitus type 2, cardiovascular diseases and some types of cancer, as well as the functional limitations associated with advancing age and disability later on the life.

In conclusion, additional studies are necessary to identify recommended PAL and energy requirement needed for optimal health and function in the Chinese elderly population of advanced age, on the basis of a diet of nutrient-rich foods supplying adequate intake for all essential nutrients and avoiding processed foods rich in refined carbohydrates and partially hydrogenated oils.

\section{Acknowledgment}

We thank the devoted and hardworking staff members of Huayang Nursing Home. This study would not have been possible without the dedication and cooperation of each of the study volunteers.

\section{References}

1. Hays NP, Roberts SB (2006) The anorexia of aging in humans. Physiol Behav 88: 257-266.

2. Yannakoulia M, Tyrovolas S, Pounis G, Zeimbekis A, Anastasiou F, et al (2011) Correlates of low dietary energy reporting in free-living elderly: The MEDIS study. Maturitas 69: 63-68.

3. Song MY, Ruts E, Kim J, Janumala I, Heymsfield S, et al. (2004) Sarcopenia and increased adipose tissue infiltration of muscle in elderly African American women. Am J Clin Nutr 79: 874-880.

4. Fontana L, Klein S (2007) Aging adiposity, and calorie restriction. JAMA 297 986-994.

5. Manini TM, Everhart JE, Patel KV, Schoeller DA, Colbert LH, et al. (2006) Daily activity energy expenditure and mortality among older adults. JAMA 296: 171179. 
Citation: Wang J, Liu Y, Aikebaier A, Tong Z, Zhang Y, et al. (2012) Nutritional Status of 35 Elderly People Residing in a Nursing Home: A Dual Challenge of Energy Surplus and Nutrient Insufficiency. J Nutr Disorders Ther S5:001. doi:10.4172/2161-0509.S5-001

Page 4 of 4

6. Kelley GA, Kelley KS (2006) Effects of aerobic exercise on C-reactive protein body composition, and maximum oxygen consumption in adults: a metaanalysis of randomized controlled trials. Metabolism 55: 1500-1507.

7. Matsuo T, Okura T, Nakata Y, Yabushita N, Numao S, et al. (2007) The influence of physical activity-induced energy expenditure on the variance in body weight change among individuals during a diet intervention. Obes Res Clin Practice 1: 109-117.

8. Zhai FY (2008) Follow-up Study on Transition of Dietary Pattern and Nutritional Status in Chinese Residents (Chinese). Beijing: Science Press p.22-24.

9. Yang YX, Wang GY, Pan XC (2002) Chinese Food Composition Table 2002 (Chinese). Beijing: Peking University Medical Press.

10. Yang YX (2005) Chinese Food Composition Table 2004 (Chinese). Beijing Peking University Medical Press.

11. Zhou B, Cooperative Meta-analysis Group of China Obesity Task Force (2002) Predictive values of body mass index and waist circumference to risk factors of related diseases in Chinese adult population. Chin $\mathrm{J}$ Epidemiol (Chinese) 23: 5-10.

12. FAO (2006) Human energy requirements - A report of FAO/WHO/UNU joint expert committee. He Zj selected interpretion. Foreign Medical Sciences (Section Hygiene, Chinese) 33: 1-21.

13. Chinese Nutrition Society (2000) Chinese Dietary Reference Intakes (Chinese) Beijing: China Light Industry Press 57,80,102,33,25,7.

14. Liu JM, Sun R, Gou LY, Piao JH, Tian Y, et al. (2008) Basal metabolic rate of female young adults in north China. Acta Nutrimenta Sinica (Chinese) 30: 31-34

15. Xia SM, Cai W, Tang QY, et al. (2002) Resting energy expenditure in the healthy elderly people. Acta Nutrimenta Sinica (Chinese) 24: 347-351.

16. Liu HY, Lu YF, Chen WJ (1995) Predictive equations for basal metabolic rate in Chinese adults: a cross-validation study. J Am Diet Assoc 95: 1403-1408.

17. Volkert D, Kreuel K, Heseker $H$, Stehle $P$ (2004) Energy and nutrient intake of young-old, old-old and very-old elderly in Germany. Eur J Clin Nutr 58: 11901200.

18. Wyka J, Biernat J, Mikołajczak J, Piotrowska E (2012)Assessment of dietary intake and nutritional status (MNA) in Polish free-living elderly people from rural environments. Arch Gerontol Geriatrt 54: 44-49.
19. Barr SI, McCarron DA, Heaney RP, Dawson-Hughes B, Berga SL, et al. (2000) Effects of increased consumption of fluid milk on energy and nutrient intake, body weight, and cardiovascular risk factors in healthy older adults. J Am Diet Assoc 100: 810-817.

20. Gallagher D, Visser M, Wang Z, Harris T, Pierson RN Jr, et al. (1996) Metabolically active component of fat-free body mass: influences of age, adiposity, and gender. Metabolism 45: 992-997.

21. Wang Z, Heshka S, Heymsfield SB, Shen W, Gallagher D (2005) A cellularlevel approach to predicting resting energy expenditure across the adult years. Am J Clin Nutr 81: 799-806.

22. Song MY, Ruts E, Kim J, Janumala I, Heymsfield S, et al. (2004) Sarcopenia and increased adipose tissue infiltration of muscle in elderly African American women . Am J Clin Nutr 79: 874-880.

23. National Institutes of Health (1998) Clinical guidelines on the identification, evaluation, and treatment of overweight and obesity in adults-the evidence report. Obes Res 6: 51-209.

24. (2000) Obesity: preventing and managing the global epidemic: report of a WHO consultation. World Health Organ Tech Rep Ser 894: 1-253.

25. (2000) US Department of Health and Human Services. Healthy People 2010 Washington, DC: US Government Printing Office.

26. Koh-Banerjee P, Chu NF, Spiegelman D, Rosner B, Colditz G, et al. (2003) Prospective study of the association if changes in dietary intake, physical activity, alcohol consumption, and smoking with 9-y gain in waist circumference among 16,587 men. Am J Clin Nutr 78: 719-727.

27. Ekelund U, Brage S, Franks PW, Hennings S, Emms S, et al. (2005) Physical activity energy expenditure predicts changes in body composition in middleaged healthy whites: effect modification by age. Am J Clin Nutr 81: 964-969.

28. Gomez-Cabello A Pedrero-Chamizo R, Olivares PR, Luzardo L, Juez Bengoechea A, et al. (2011) Prevalence of overweight and obesity in noninstitutionalized people aged 65 or over from Spain: the elderly EXERNET multi-centre study. Obes Rev 12: 583-592.

29. Kahn EB, Ramsey LT, Brownson RC, Heath GW, Howze EH, et al. (2002) The effectiveness of interventions to increase physical activity. A systematic review. Am J Prev Med 22: 73-107
This article was originally published in a special issue, Nutrition and Health handled by Editor(s). Dr. Karen S. Kubena, Texas A\&M University, USA 